\title{
LA BIBLIA Y LA IGLESIA: REVISANDO LO OBVIO
}

\author{
Elias Brasil de Souza ${ }^{1}$
}

\begin{abstract}
Resumen
Las circunstancias culturales, intelectuales y sociales actuales indican que, al avanzar hacia el futuro, la postura de la iglesia sobre la autoridad de la Biblia enfrentará desafíos cada vez más difíciles en todos los sectores. Las controversias teológicas, los dilemas éticos y las demandas culturales gradualmente forzarán a la iglesia — en medio de una tormenta de criticismo, duda y presión social - a tomar una postura clara sobre temas cruciales. Teniendo en consideración el realismo de este escenario, el siguiente estudio pretende responder a las siguientes preguntas: ¿Cómo puede sobrevivir la Iglesia? ¿Cómo puede la Iglesia preservar su identidad en medio de los cambios sociales y los desafíos presentados por el fundamento moral inestable de la sociedad contemporánea?
\end{abstract}

Palabras clave: Biblia, iglesia, autoridad, cultura

\footnotetext{
${ }^{1}$ Doctor en Teología por la Universidad Andrews, Estados Unidos. Director del Instituto de Investigación Bíblica de la Asociación General de los Adventistas del Séptimo Día. Email: SouzaE@gc.adventist.org
} 


\title{
THE BIBLE AND THE CHURCH: REVISITING THE OBVIOUS
}

\begin{abstract}
The current cultural, intellectual, and social circumstances indicate that as the church moves toward the future, its stance on biblical authority will face increasing challenges from every corner. Theological controversies, ethical dilemmas, and cultural demands will increasingly force the church —amidst turmoil of criticism, doubt, and social pressures - to take a clear stand on crucial issues. Given the realism of this scenario, this study will respond the following questions: How can the church survive? How can the church preserve its identity through the changes and the challenges posed by the unstable moral foundation of contemporary society?
\end{abstract}

Keywords: Bible, church, authority, culture 


\section{Introducción}

Desde sus inicios, la Iglesia Adventista del Séptimo Día ha estado comprometida con la Biblia y la Biblia sola para establecer su sistema de creencias y formar su misión. La Biblia también ha jugado un papel importante en el ministerio profético de Elena G. de White y ha mantenido al movimiento adventista a través de tiempos difíciles de confusión teológica.

Las circunstancias culturales, intelectuales y sociales actuales indican que, al avanzar hacia el futuro, la postura de la Iglesia sobre la autoridad de la Biblia enfrentará desafíos cada vez más difíciles en todos los sectores. Las controversias teológicas, los dilemas éticos y las demandas culturales gradualmente forzarán a la Iglesia (en medio de una tormenta de criticismo, duda y presión social) a tomar una postura clara sobre temas cruciales. Dado el realismo de este escenario, uno se puede preguntar: ¿Cómo puede sobrevivir la Iglesia? ¿Cómo puede la Iglesia preservar su identidad en medio de los cambios sociales y los desafíos presentados por el fundamento moral inestable de la sociedad contemporánea?

\section{Fuentes de autoridad teológica}

Al lidiar con los desafíos mencionados anteriormente, algunas personas podrían apelar a la tradición; otras, a la razón y a la experiencia. Algunos creyentes bienintencionados podrían apelar a la comunidad como una base de autoridad suprema. Lamentablemente, todas estas autoridades mencionadas, por más útiles y convenientes que sean, no son suficientemente fuertes para funcionar como el fundamento sólido que la Iglesia necesita para enfrentar los desafíos que nos esperan. La tradición, como fuente última de autoridad teológica, fue examinada por los reformadores, que expusieron su deficiencia basados en la revelación bíblica. Por más buena que sea, y por supuesto que hay tradición buena (ver 1 Cor 11:2), nunca puede en sí misma funcionar como el fundamento último 
para las creencias y los procedimientos de la Iglesia. Debido a su misma naturaleza, la tradición es siempre cambiante degenera en tradicionalismo con facilidad. Como dice J. Pelikan: "La tradición es la fe viviente de los muertos; el tradicionalismo es la fe muerta de los vivientes". ${ }^{1}$ Aunque no es mala en sí misma, la tradición es deficiente como fuente superior de autoridad para juzgar aseveraciones y corregir rumbos.

Pero ¿qué podemos decir de la razón? Aunque la razón puede ser una opción viable, las dos guerras mundiales que sumieron a la humanidad en matanzas sin precedentes en nuestra corta historia humana, y cuya culminación fue el Holocausto, han demostrado ampliamente que no es confiable. Tales atrocidades, perpetradas por naciones iluminadas, revelan que el intelecto visionario no pasa la prueba de confiabilidad absoluta en materias relacionadas con el bien último.

En cuanto a los valores humanos y la búsqueda del bien supremo, el ideal Cartesiano seguido por la obsesión del Iluminismo, que hace de la razón el centro máximo de autoridad ha probado ser, más allá de toda duda, un fracaso total. La razón, como parte de la imagen de Dios en la humanidad, tiene un papel obvio e indispensable en la aprehensión de información y en el procesamiento del conocimiento. Sin embargo, también está profundamente afectada por el pecado y, por lo tanto, necesita una fuente de autoridad superior a ella misma para juzgar y corregir sus caminos.

Más recientemente, la comunidad ha sido presentada como una opción viable de autoridad suprema. Según esta postura, la comunidad de creyentes ha de determinar la verdad, y decidir lo que está bien y lo que está mal. Sin embargo, la comunidad no es un fundamento confiable de autoridad máxima. Aunque yace en el corazón de lo que significa ser

*Este artículo fue publicado por primera vez como "The Bible and the Church: Revisiting the Obvious", Reflections-The BRI Newsletter 41(Jan., 2013): 1-5. Usado con permiso. Traducido por el Staff de ACES.

'Jaroslav Pelikan, The Vindication of Tradition, The 1983 Jefferson Lecture in the Humanities (New Haven: Yale University Press, 1984), 65. 
una Iglesia y se valora mucho su autoridad, la comunidad también ha sido afectada por el pecado y, en consecuencia, es obvio que no está libre de fracasos. Las comunidades (religiosas o no) han perpetrado actos horribles contra otros seres humanos.

A finales del siglo XX, comunidades enteras estuvieron a punto de ser aniquiladas, ya fuera por motivos religiosos, raciales u otros. Por lo tanto, por mucho que uno pueda respetar la autoridad de la comunidad, se vuelve evidente que esta no es un cimiento confiable de autoridad suprema. La comunidad debe estar subordinada a una autoridad superior, a fin de decidir lo que está bien y lo que está mal.

En el intento por resolver los problemas ligados a la razón, la tradición y la comunidad, uno podría señalar que el Espíritu Santo, al iluminar a los creyentes, es el fundamento supremo de autoridad. Aunque esta sugerencia pareciera ser absolutamente correcta a primera vista, deberíamos recordar que no pocas veces las apelaciones al Espíritu se transforman en formas sutiles de legitimar la propia experiencia subjetiva. Aun al apelar al Señor Jesucristo, como fuente suprema de autoridad en cuestiones teológicas, el creyente corre el riesgo de argumentar sobre la base de un Jesús reconstruido según sus propias preferencias personales o culturales.

El poder del Espíritu y el señorío de Jesús, ciertamente, juegan un papel fundamental para resolver desacuerdos teológicos. Sin embargo, podría surgir el cuestionamiento en cuanto a cómo uno puede estar seguro de que cierto curso de acción está siendo motivado por el Espíritu y representa el señorío de Jesús. Una vez más, al apelar indiscriminadamente al Espíritu Santo o a Jesús, se corre el riesgo de reemplazar a Jesús y/o al Espíritu por la razón o la experiencia, la tradición o la comunidad, y de este modo identificar los propios deseos y preferencias con la voluntad de Jesús y/o la dirección del Espíritu Santo.

Entre esas fuentes de autoridad tan importantes, aunque limitadas y restringidas, la Biblia emerge como el estándar único y absoluto para juzgar toda otra autoridad. Semejante postulado surge natural- 
mente del ejemplo de Jesús y las declaraciones de autenticación propia de las Escrituras mismas.

No se requiere mucho esfuerzo para notar que, según los Evangelios, Jesús consideraba a la Escritura como la corte suprema de apelaciones y, repetidamente, la señaló para clarificar algún tema o resolver un debate. En su apelación a un pasaje bíblico, Jesús aseveró con absoluta convicción: "[. . . ] la Escritura no puede ser quebrantada” (Jn 10:34, 35).

Las Escrituras afirman, vez tras vez, que lo que se está diciendo proviene de Dios. Escribiéndole a Timoteo, Pablo afirmó: "que desde la niñez has sabido las Sagradas Escrituras, las cuales te pueden hacer sabio para la salvación por la fe que es en Cristo Jesús”. “Toda la Escritura es inspirada por Dios, y útil para enseñar, para redargüir, para corregir, para instruir en justicia, a fin de que el hombre de Dios sea perfecto, enteramente preparado para toda buena obra" (2 Tim 3:15-17). Este texto clásico afirma el origen divino de la Biblia, con sus consiguientes implicaciones para su inspiración y autoridad. Evalúa las Escrituras como provechosas y clarifica su propósito: "hacer sabio para la salvación". Sobre la base de la aseveración de las Escrituras mismas, en cuanto a su origen y propósito, estamos justificados para tomar la Biblia como la sede suprema de autoridad.

La epístola a los Hebreos declara: "Dios, habiendo hablado muchas veces y de muchas maneras en otro tiempo a los padres por los profetas, en estos postreros días nos ha hablado por el Hijo, a quien constituyó heredero de todo, y por quien asimismo hizo el universo" (Heb 1:1, 2).

Este corto pasaje ilustra y encapsula el canon entero. En el Antiguo Testamento, Dios nos habla "de muchas maneras por medio de los profetas". En el Nuevo Testamento, Dios nos habla "a través del Hijo". Por lo tanto, solamente las Escrituras son capaces de guiarnos para salir del laberinto de tantas opciones éticas y puntos de vista teológicos que compiten por aceptación en una cultura de relativismo y consumismo. Solamente al aceptar las aseveraciones de auto-autenticación de la Biblia y al tomar en consideración su autoridad absoluta, podrá la Iglesia resolver 
sus dilemas y aun así permanecer unida bajo el señorío de Jesucristo. ${ }^{2}$

A fin de saber qué camino debemos elegir como iglesia corporativa y como miembros individuales de la Iglesia, no hay otra opción que volvernos a las Escrituras. Después de todo, la Biblia claramente manifiesta sus afirmaciones de auto-autenticación como la suprema corte de apelación en todos los asuntos teológicos y prácticos para la Iglesia. Como lo expresa el conocido pasaje de Isaías: “ ¡A la ley y al testimonio! Si no dijeren conforme a esto, es porque no les ha amanecido” (Isa 8:20; cf. 2 Tim 3:16, 17).

\section{Relevancia de las Escrituras}

La revelación de las Escrituras es el medio más objetivo y fundamental que Dios emplea para comunicar su voluntad a la iglesia. Aun cuando desarrollos modernos en las ciencias sociales, la semiología y la teoría lingüística, han remarcado la importancia de variados significados y procesos de comunicación, incluida la no verbal, la palabra permanece como el instrumento primario y fundamental para la interacción interpersonal y las relaciones. ${ }^{3}$

Dotados de la imagen de Dios, los seres humanos recibieron del Creador la habilidad de la comunicación objetiva y verbal como ningún otro de los seres de la creación que habitan este planeta. Como si esto no fuera suficiente, Dios reveló su voluntad a los seres humanos por medio de las palabras. Y a través de la Biblia establece relaciones y guía a su pueblo. El poder eficaz de la Palabra de Dios en crear y regenerar, omnipresente desde el Génesis hasta el Apocalipsis, se expresa en forma concisa en Isaías 40:8: "La hierba se seca, la flor se cae; pero la Palabra de nuestro Dios permanece para siempre".

${ }^{2}$ Ver el estudio realizado por Kwabena Donkor, "Contemporary Responses to Sola Scriptura: Implications for Adventist Theology”, Reflections - The BRI Newsletter 41 (Jan., 2013), 5-8.

${ }^{3}$ Vern S. Poythress, In the Beginning was the Word: Language: A God-Centered Approach (Wheaton, IL: Crossway Books, 2009), 11-38. 
La Palabra de Dios afirma tener autoridad sobre todas las áreas y dimensiones de la vida individual y de la iglesia. Los siete puntos desarrollados a continuación solamente ejemplifican algunas áreas que requieren atención, si deseamos ser fieles a las demandas detalladas y magnánimas de las Escrituras.

\section{Ensalzando la Biblia en el servicio a Dios}

Los teólogos y profesores de Biblia tienen la solemne responsabilidad de poner los estudios al servicio de Dios y de su Palabra. Hace más de treinta ańos, James Smart escribió su libro titulado The Strange Silence of the Bible in the Church: A Study in Hermeneutics. ${ }^{4}$ Esta obra argumenta que, aunque la Biblia ha sido producida en masa y ha aumentado el conocimiento académico que se tiene de ella, este conocimiento no ha llegado a las personas. Por lo tanto, el tremendo desafío que enfrenta la iglesia actual no es la ignorancia del mensaje de la Biblia, sino el silenciamiento de la autoridad de su voz. Un análisis reciente de trabajos bíblicos y teológicos producidos por eruditos conservadores parece indicar el silenciamiento de algunas declaraciones centrales de la Biblia. Por ejemplo, se podría mencionar el creciente escepticismo de algunos catedráticos evangélicos acerca de la literalidad e historicidad del relato de la creación del Génesis, acompañado por la tendencia a aceptar la evolución. ${ }^{5}$

Esta situación coloca una gran responsabilidad sobre los hombros de los eruditos adventistas. Con una desconcertante variedad de marcos teóricos y opciones metodológicas disponibles en la comunidad académi-

${ }^{4 j}$ ames D. Smart, The Strange Silence of the Bible in the Church: A Study in Hermeneutics (Filadelfia: Westminster Press, 1976), 142.

${ }^{5}$ Ver, por ejemplo, Peter Enns, The Evolution of Adam: What the Bible Does and Doesn't Say About Human Origins (Grand Rapids, MI: Brazos Press, 2012); John H. Walton, Genesis 1 as Ancient Cosmology (Winona Lake, IN: Eisenbrauns, 2011); Bruce K. Waltke y Charles Yu, An Old Testament Theology: An Exegetical, Canonical, and Thematic Approach (Grand Rapids, MI: Zondervan, 2007), 153. 
ca, deben utilizar sus habilidades al máximo para optar por los métodos y presuposiciones correctos al interpretar la Biblia. Sumado a esto, la combinación de integridad académica y humildad, permanece como el estándar para cada catedrático y teólogo bíblico. La autoridad del intérprete bíblico debe estar subordinada a la de la Biblia, y las opiniones particulares deben ser sometidas humildemente a la evaluación de los pares y en última instancia a la de la iglesia. Al combinar el trabajo competente con la oración y la confianza en el Espíritu, los teólogos y profesores de Biblia continuarán siendo una bendición para la iglesia, siempre y cuando ayuden a lograr una mejor comprensión y aplicación de la Palabra de Dios. Las palabras de Malaquías dirigidas a los sacerdotes de Israel, se aplican con exactitud a los teólogos y profesores de Biblia adventistas: "Porque los labios del sacerdote han de guardar la sabiduría, y de su boca el pueblo buscará la Ley; porque es mensajero del Señor Todopoderoso" (Mal 2:7).

\section{La Biblia y el liderazgo en la iglesia}

Los líderes de la iglesia deben permitir que la Biblia determine su estilo de liderazgo. En ella se encuentra "la mayor colección de estudios de liderazgo jamás escrito, con conocimientos tremendamente útiles para los líderes y administradores de hoy". ${ }^{6}$ En asuntos de administración y liderazgo en la iglesia, la Biblia no solo es esencial por sus "casos de estudio”, sino también por los principios de liderazgo que contiene. Las técnicas de administración pueden tener un lugar dentro de la marcha general de la iglesia; pero sin la Biblia, estas herramientas potencialmente muy útiles, pueden llegar a ser nada más que modelos seculares de eficiencia y profesionalismo. Los líderes de la iglesia son llamados no solamente a promover la predicación de Jesús, sino también a seguir su estilo administrativo y de liderazgo. No son llamados a actuar o a comportarse como

${ }^{6}$ Lorin Woolfe, The Bible on Leadership: From Moses to Matthew: Management Lessons for Contemporary Leaders (Nueva York: MJF Books, 2003), ix. 
ejecutivos o gerentes, sino como líderes semejantes a Jesús. "Apacentad la grey de Dios que está entre vosotros, cuidando de ella, no por fuerza, sino voluntariamente; no por ganancia deshonesta, sino con ánimo pronto; no como teniendo señorío sobre los que están a vuestro cuidado, sino siendo ejemplos de la grey. Y cuando aparezca el Príncipe de los pastores, vosotros recibiréis la corona incorruptible de gloria” (1 Ped 5:2-4; RV 1995).

\section{La Biblia y la vida de oración}

La oración debe tener una orientación bíblica. De acuerdo a las Escrituras, debe ser ofrecida con el reconocimiento de la santidad de Dios y la pecaminosidad humana. La oración bíblica no funciona como una rutina para manipular a Dios, sino como un medio de comunicación y comunión entre los pecadores y un Creador y Redentor misericordioso. El siguiente pasaje captura una importante dimensión de la oración bíblica: "Buscad al Señor mientras puede ser hallado, llamadlo en tanto que está cerca. Deje el impío su camino, y el hombre malo sus pensamientos; y vuélvase al Señor, quien tendrá de él misericordia, y a nuestro Dios, que es amplio en perdonar. Porque mis pensamientos no son vuestros pensamientos, ni vuestros caminos mis caminos, dice el Señor" (Isa 55:6-8).

\section{La Biblia y el evangelismo}

El evangelismo debe estar bíblicamente orientado. A pesar de que hay muchas maneras legítimas de motivar a las personas para que se acerquen a Jesús, la predicación de la Palabra debe permanecer como eje central en los planes misioneros de la iglesia. Por sobre los diferentes métodos empleados para acercar las multitudes a Jesús, deben ser hechos grandes esfuerzos para llevarlos a confiar en la Palabra de Dios y a seguir al Jesús revelado en ellas. De esta manera, el evangelismo, en sus variadas expresiones, debe proclamar no solamente la persona del Salvador, sino 
que debe invitar a que la gente lo obedezca y sea fiel a su mensaje tal cual está revelado en las Escrituras. El verdadero evangelismo honra las Escrituras. Frente al rey Agripa, Pablo aclaró acerca de su predicación: "No digo nada fuera de las cosas que los profetas y Moisés dijeron que habían de suceder" (Hch 26:22). A continuación, el apóstol le hizo la pregunta decisiva: “¿Crees, rey Agripa, a los profetas?” (Hch 26:27).

\section{La Biblia en la educación cristiana}

La educación cristiana debe estar condicionada por la revelación de Dios en las Escrituras y en su sentido último, debe considerar que la Palabra de Dios está claramente expresada a través de las sabias advertencias de Dios en los muchos pasajes bíblicos que enfatizan las instrucciones, leyes, y testimonios del Señor como recursos de sabiduría. El capítulo más largo de la Biblia — Salmo 119_ está dedicado enteramente a ensalzar los beneficios de la Torá — la revelación de Dios — para el crecimiento espiritual e intelectual de los hijos de Dios. De la misma manera, otros pasajes de la Biblia hebrea no escatiman palabras para aconsejar y amonestar a quienes buscan sabiduría, para que aprecien la Palabra de Dios. Con una aguda percepción de lo que significa la educación según la Biblia, Martín Lutero escribió esta tan citada declaración: "Temo mucho que las universidades sean anchas puertas del infierno, si no se aplican cuidadosamente a explicar la Escritura Santa y grabarla en el corazón de la juventud. Yo no aconsejaré a nadie que coloque a su hijo donde no reine la Escritura Santa. Toda institución donde los hombres no están constantemente ocupados con la Palabra de Dios se corromperá" ${ }^{7}$ De aquí la relevancia del llamado de Dios a sus hijos: "Adquiere sabiduría, adquiere inteligencia. No te olvides, ni te apartes de las razones de mi boca" (Prov 4:5).

${ }^{7}$ Citado en Mark Water, The New Encyclopedia of Christian Quotations (Alresford, Hampshire: John Hunt Publishers, 2000), 129. Ver también Elena G. de White, El conflicto de los siglos (Buenos Aires: Asociación Casa Editora Sudamericana, 2008), 151. 


\section{La Biblia y la música}

El ministerio de la música es un área importante en la vida de la iglesia, que necesita estar fundamentado en su mensaje. La música puede destacarse entre muchas formas de comunicación como un medio de transmitir la verdad. Puede haber muchos cristianos que no conozcan bien la Biblia, pero raramente exista una persona que no conozca muchos himnos o canciones religiosas. Los conflictos que involucran los estilos musicales y los instrumentos, han envuelto a algunas congregaciones, pero no debemos ignorar la importancia de las letras de estos cánticos. Su mensaje debe estar en armonía con la enseñanza de la Escritura. Los compositores y músicos de la iglesia tienen el deber sagrado de producir y ejecutar música de iglesia de tal forma que comunique un mensaje consistente con el carácter de Dios revelado en las Escrituras. “ Cantad a Dios, cantad! ¡Cantad a nuestro Rey, cantad! Porque Dios es el Rey de toda la tierra, cantad con inteligencia” (Sal 47:6-7).

\section{La Biblia y la adoración}

La adoración en la iglesia debe brindar un lugar importante a la lectura y a la predicación de las Escrituras. El servicio de adoración no debe transformarse en un sitio para tantos anuncios y propagandas de las actividades y programas de la iglesia que casi no deje tiempo para la presentación de la Palabra de Dios. Cuando los miembros del pueblo de Dios se reúnen para adorar, necesitan recibir la Palabra para ayudarlos a enfrentar las pruebas, desánimos y desafíos de la vida cotidiana. Nada debería impedir o remplazar la proclamación de la Palabra. Los predicadores que usan el púlpito para relatar historias personales sin una exposición bíblica responsable o para entretener y divertir a su público, están traicionando su llamado y profanando el púlpito. Lo que Pablo escribió en 1 Corintios 2:2 debería transformarse en la brújula de orientación de 
todo predicador. "Porque me propuse no saber nada entre vosotros, sino a Jesucristo, y a este crucificado".

La predicación debe apoyarse en un vasto estudio e investigación de las Escrituras. La Biblia no funciona meramente como un libro de recetas o de referencias. No siempre otorga respuestas fáciles y prontas para algunas de las desafiantes circunstancias de la vida. Puede ser que no encontremos un pasaje específico o un versículo para cada enfermedad espiritual o problema personal ${ }^{8}$ pero si es correctamente interpretada, ciertamente provee la respuesta suprema para las preguntas más cruciales de la vida, y para los asuntos relacionados a los procedimientos de la iglesia; la relevancia de la Biblia trasciende la suma de sus partes.

Como registro escrito del plan global de Dios para redimir al mundo del pecado, la Biblia ofrece a su pueblo una visión del mundo, una metanarrativa, que abarca desde la creación hasta la nueva creación. Aunque algunos pasajes y textos individuales pueden traer consuelo en situaciones de tristeza y sufrimiento, y ser de guía para circunstancias específicas, nunca deberíamos perder de vista las interconexiones orgánicas entre los variados pasajes y temas de la Biblia en el gran panorama del plan de salvación. De esta manera, le incumbe a cada predicador hacer la unidad, veracidad y autoridad de la Biblia, clara y accesible para la audiencia. Deben prestar atención al consejo de Pablo a Timoteo: "Procura con diligencia presentarte a Dios aprobado, como obrero que no tiene de qué avergonzarse, que expone bien la Palabra de verdad" (2 Tim 2:15).

\section{Conclusión}

La Biblia se mantiene como el fundamento absoluto sobre el cual la iglesia debe basar su teología y prácticas. Como enfatiza Pablo: "Así como Cristo amó a la iglesia, y se entregó a sí mismo por ella, para san-

${ }^{8}$ Ekkehardt Mueller, "Hermeneutical Guidelines for Dealing with Theological Questions", Reflections-The BRI Newsletter 40 (Oct., 2012), 1-6. 
tificarla y limpiarla en el lavado del agua, por la Palabra, para presentarla para sí, una iglesia gloriosa, sin mancha ni arruga, ni cosa semejante; antes, que sea santa e inmaculada" (Efe 5:25-27). De esta manera, para poder permanecer fiel al Señor, la iglesia debe levantar constantemente la Palabra de Dios como la autoridad suprema para ordenar sus creencias y juzgar su práctica y experiencia.

Recibido: 11/12/2015

Aceptado: 05/03/2016 